\title{
A Descriptive Epidemiology Study of Oral Cleft in Sergipe, Brazil
}

\author{
Andrea Luiza ${ }^{1}$ Diego Noronha de Góis ${ }^{1}$ Jadson Alípio Santana de Sousa Santos ${ }^{1}$ \\ Rosany Larissa Brito de Oliveira ${ }^{1} \quad$ Luiz Carlos Ferreira da Silva ${ }^{1}$
}

\author{
1 Department of Dentistry, Federal University of Sergipe (UFS), \\ Aracaju/SE, Brazil
}

Int Arch Otorhinolaryngol 2013;17:390-394.
Address for correspondence Dr. Luiz Carlos Ferreira da Silva, PhD, Department of Dentistry, University Hospital, Claudio Batista, s/n-Sanitarium, Aracaju/SE 49060-100, Brazil (e-mail: Icsilva@ufs.br).

\begin{abstract}
Introduction The nonsyndromic orofacial cleft is the fourth most common birth defect, but in Brazil, data about the cleft epidemiology are not accurate.

Objective This study aimed to describe the epidemiologic characteristics of oral cleft cases at Specialized Society Attending Cleft Patient in Sergipe State.

Methods Data were obtained from patients' medical records in relation to the following characteristics: age; gender; race; origin; cleft type; additional malformations and/or complications; prenatal accomplishment; treatment applied. For diagnosis analysis, it was noted if mothers had received prenatal care and if they had ultrasonography performed and if the cleft was viewed in it.

Results We observed a prevalence of male gender (54\%). Age between 0 and 4 years old was most prevalent (53\%), and pheoderma race was observed in $47 \%$. Transincisive foramen cleft was found in $52.3 \%$ of the individuals. The prevalence of pre- and transincisive foramen cleft was higher in men (66.3 and 55.7\%), women accounted for $65.0 \%$ of postincisive foramen, and atypical facial cleft $(0.3 \%)$ occurred in one case. Associated malformations and complications were present in $12 \%$ of patients. Prenatal care was reported by $48 \%$ of the mothers.

Conclusion In this study male gender was the most affected, and 0 to 4 years was the

Keywords

- cleft lip

- cleft palate

- epidemiology most frequent age group. Transincisive foramen cleft type was most frequently encountered. Prenatal care was reported by most mothers. So, this study found that early treatment is a reality in SEAFESE (Service Specializing in Cleft Care of Sergipe), and consequently the chances of successful integration of the child to society will be better.
\end{abstract}

\section{Introduction}

The nonsyndromic orofacial cleft is the fourth most common birth defect, besides being the most observed craniofacial malformation. ${ }^{1,2}$ Although its etiology still remains unclear, most likely both exogenous (teratogenic) and endogenous (genetic) factors contribute to this embryopathy in humans. ${ }^{3,4}$ In addition, it is a major oral health problem in the world and its treatment requires specialized multiprofessional and integrated actions. ${ }^{5}$
Several studies of the epidemiologic patterns of cleft deformities show a marked variability in the frequency of this anomaly, ranging from 1 in 500 to 1 in 2,500 live births. ${ }^{5}$ In Brazil, data about cleft lip and/or palate epidemiology are not accurate; however, the incidence of this malformation is 0.36 in 1,000 live births. In northeastern Brazil, the incidence is 0.39 in 1,000 live births. ${ }^{6,7}$ In Sergipe, approximately 22 new cases of cleft lip and/or palate occur each year. ${ }^{8}$ The SEAFESE (Service Specializing in Cleft Care of Sergipe) is a public interest civil social organization formed by a

Copyright $(2013$ by Thieme Publicações DOI http://dx.doi.org/ Ltda, Rio de Janeiro, Brazil 10.1055/s-0033-1352502. ISSN 1809-9777. 
Table 1 Surgical treatment protocol followed by SEAFESE

\begin{tabular}{|l|l|}
\hline Patient age & Treatment \\
\hline $0-3 \mathrm{mo}$ & Initial assessment \\
\hline $3 \mathrm{mo}$ & Cheiloplasty \\
\hline $12 \mathrm{mo}$ & Palatoplasty \\
\hline $10-12$ y & Secondary surgeries \\
\hline $12-16$ y & Secondary surgeries (rhinoplasty) \\
\hline$>17$ y & Orthognathic surgery \\
\hline
\end{tabular}

SEAFESE, Service Specializing in Cleft Care of Sergipe.

multidisciplinary team comprised of 13 professionals in the following specialties: plastic surgery, maxillofacial surgery, nurse, speech therapy, dentistry, orthodontics, psychology, social work, and anesthesiology. All surgeries performed within SEAFESE follow a protocol created by its professionals to obtain the best results for patients with cleft ( $\mathbf{- T a b l e ~} \mathbf{1}$ ).

According to that, the most detailed information about these birth defects in populations is essential to recognize and prevent the problem, and, consequently, to plan assistance policies in general. Thus, the aim of this study was to characterize the cases of cleft lip and palate based on the medical records of patients treated at the SEAFESE.

\section{Methods}

For the purpose of this study, a descriptive cross-sectional design was adopted, based on medical records of patients treated at the SEAFESE. It included all the medical records of patients attended at SEAFESE from October 2003 to June 2007. Data not reported on medical record were considered as "not defined."

All medical records were analyzed, regarding (1) demographic characteristics (gender, race, age, origin); (2) cleft diagnosis and classification (cleft type, associated malformations and complications, prenatal accomplishment); and (3) treatment applied.

The variable age was divided into 6 groups with an interval of 4 years for each group according to the classification made by the Brazilian Institute of Geography and Statistics, Population Census, 2000. ${ }^{9}$ Patients were classified according to race as leukoderma (white), pheoderma (brown), xanthoderma (yellow), and melanoderma (black); according to the origin, they were grouped based on where they live (metropolis, countryside, and other states).

Cleft classification was based on the work of Spina et al, ${ }^{10}$ which defines four groups: preincisive foramen cleft (uni- or bilateral, median); transincisive foramen cleft (uni- or bilateral); postincisive foramen clefts; and atypical (rare) facial clefts.

For diagnosis analysis, it was noted if mothers received prenatal care and if they had ultrasonography done and if the cleft was viewed in it. Regarding treatment, only surgeries to repair cleft lip and palate (lip repair and palatoplasty, respectively) were considered in this study; additional surgeries performed in patients with cleft were included as "other surgeries."

The collected data were tabulated and calculated in Excel for Windows 2003, and the data are presented in absolute frequencies and percentages.

This study was approved by the Committee on Ethics in Research Involving Humans, from Federal University of Sergipe (CEP-UFS/CAAE No.: 0082.0.107.000-07).

\section{Results}

A total of 350 medical records were achieved. The general analysis of the data allows tracing back the profile of participants, as shown in - Table 2 . In relation to gender, $54.0 \%$ of patients who comprised the sample were male; the distribution of patients by age focused predominantly between 0 and 14 years (77.4\%), with a higher prevalence in the age group of 0 to 4 years. Regarding race, 165 patients (47.2\%) were pheoderma and 146 (41.7\%) leukoderma. Finally, most of them were from the countryside (58.0\%).

- Table 3 shows patient distribution according to cleft type and gender. The most frequent type of cleft was the transincisive foramen, with 183 cases (52.3\%), and this cleft was more frequent in males, with 102 cases (55.7\%). The second most frequent type of cleft was the preincisive foramen, with 89 cases (25.4); this cleft was also more frequent in males,

Table 2 Distribution of oral cleft cases by gender, age group and race

\begin{tabular}{|c|c|c|}
\hline & $n$ & $\%$ \\
\hline \multicolumn{3}{|l|}{ Gender } \\
\hline Male & 189 & 54.00 \\
\hline Female & 161 & 46.00 \\
\hline \multicolumn{3}{|l|}{ Age group (y) } \\
\hline$<4$ & 188 & 53.70 \\
\hline $5-9$ & 44 & 12.60 \\
\hline $10-14$ & 39 & 11.10 \\
\hline $15-19$ & 31 & 8.90 \\
\hline $20-24$ & 24 & 6.90 \\
\hline$>25$ & 24 & 6.90 \\
\hline \multicolumn{3}{|l|}{ Race } \\
\hline Pheoderma & 165 & 47.20 \\
\hline Leukoderma & 146 & 41.70 \\
\hline Xanthoderma & 0 & 0.00 \\
\hline Melanoderma & 14 & 4.00 \\
\hline Not defined & 25 & 7.10 \\
\hline \multicolumn{3}{|l|}{ Origin } \\
\hline Countryside & 203 & 58.00 \\
\hline Metropolis & 133 & 38.00 \\
\hline Other states & 10 & 2.90 \\
\hline Not defined & 4 & 1.10 \\
\hline
\end{tabular}


Table 3 Distribution of patients according to cleft type and gender

\begin{tabular}{|l|l|l|l|l|l|}
\hline \multirow{2}{*}{ Cleft type } & Gender & Total (\%) \\
\cline { 2 - 5 } & Male & $\%$ & Female & $\%$ & \\
\hline Preincisive foramen & 59 & 66.3 & 30 & 33.7 & $89(25.4)$ \\
\hline Postincisive foramen & 27 & 35.0 & 50 & 65.0 & $77(22.0)$ \\
\hline Transincisive foramen & 102 & 55.7 & 81 & 44.3 & $183(52.3)$ \\
\hline Atypical (rare) facial & 01 & 100.0 & 00 & 0.0 & $01(0.3)$ \\
\hline
\end{tabular}

with 59 cases (66.3\%). The third most frequent type of cleft was the postincisive foramen, with 77 cases (22.0\%), and this cleft occurred more often in females with 50 cases (65.0\%). Finally, the atypical (rare) facial cleft was less frequent, with only 1 case $(0.3 \%)$, a male.

Among the 350 medical reports analyzed, only 41 (12.0\%) showed data regarding malformations and additional complications in the patients, without specifying. Prenatal care was reported by almost half the sample ( $168 ; 48.0 \%)$, and only 26 mothers (7.0\%) reported on prenatal care. In 156 records (45.0\%), this information was missing. According to information provided by patients to fill the medical record, only in 7 cases $(4.2 \%)$ of 168 referred to prenatal care did the ultrasonography reveal the cleft; in 107 cases (63.7\%), nothing was detected, and in 54 (32.1\%) there was no information (not defined).

Associated malformations and complications occurred in 41 individuals, more frequently in men (26 subjects; 63.4\%). The associated malformations and complications can be seen in -Table 4.

Since 2003, when the service was available, 173 surgeries were performed in patients with cleft (-Table 5): 77 cheiloplasty, 79 palatoplasty, and 17 other surgeries (fistuloplasty, rhinoplasty, otoplasty). The highest rate was recorded in 2004 (69 surgeries) and the lowest in 2007 (3 surgeries). This decrease in the number of surgeries was due to a change in SEAFESE head office.

- Table 6 shows the distribution of patients by age at initial assessment in SEAFESE and treatment accomplished. Demand for service was greater in the first 4 years of life; consequently, due to surgical protocol adopted by the institution, lip repair was the most performed surgery.

\section{Discussion}

This study showed a demand for an early access to the service, especially during the first 4 years of life ( - Table 1 ); the literature is in consensus that the primary surgery for cleft lip and/or palate repair is usually performed in all children before 2 years of age. ${ }^{11}$ The high concentration of patients attending in this service within this age group suggests that people are getting more conscious about the services directed to cleft treatment. Moreover, the early access to specialist services allows the structuring of a safer and easier treatment plan with a more favorable prognosis, as well as consequent
Table 4 Associated malformations and complications

\begin{tabular}{|c|c|c|}
\hline \multirow{2}{*}{$\begin{array}{l}\text { Associated malformations } \\
\text { and complications }\end{array}$} & \multicolumn{2}{|c|}{ Gender } \\
\hline & Male & Female \\
\hline Premature & 4 & 3 \\
\hline Limbs deformity + premature & 1 & 0 \\
\hline $\begin{array}{l}\text { Treacher Collins syndrome } \\
\text { (ears deformity) }\end{array}$ & 1 & 0 \\
\hline Cerebral palsy & 1 & 1 \\
\hline Limbs deformity + anemia & 1 & 0 \\
\hline Diabetics & 1 & 0 \\
\hline Lacrimal duct obstruction & 1 & 0 \\
\hline $\begin{array}{l}\text { Apert syndrome }+ \text { syndactyly } \\
\text { (hands and feet) }\end{array}$ & 1 & 0 \\
\hline Telecanthus, ozena syndrome & 1 & 0 \\
\hline Delay in bone growth & 1 & 0 \\
\hline Congenital cataract-left eye & 1 & 0 \\
\hline Supernumerary finger-left hand & 1 & 0 \\
\hline Developmental delay & 0 & 1 \\
\hline Breathing problems at birth & 2 & 1 \\
\hline Hydrocephalus + neurologic problems & 3 & 0 \\
\hline Ptosis & 1 & 0 \\
\hline Congenital heart disease & 0 & 1 \\
\hline Syndromic face & 1 & 0 \\
\hline Epilepsy & 1 & 0 \\
\hline $\begin{array}{l}\text { Tessier syndrome }+ \\
\text { asthma }+ \text { visually impaired }\end{array}$ & 0 & 1 \\
\hline Displacement of gestational sac & 0 & 1 \\
\hline $\begin{array}{l}\text { Polydactyly associated with } \\
\text { syndactyly + Parenteral } \\
\text { consanguinity }\end{array}$ & 0 & 1 \\
\hline $\begin{array}{l}\text { Agenesis of the right } \\
\text { forearm and hand }\end{array}$ & 0 & 1 \\
\hline Visually impaired & 0 & 2 \\
\hline Neurological problems & 0 & 1 \\
\hline Malformation widespread & 3 & 1 \\
\hline Total & 26 & 15 \\
\hline
\end{tabular}


Table 5 Distribution of patients according to the treatment over the years

\begin{tabular}{|c|c|c|c|c|c|c|c|}
\hline \multirow[t]{2}{*}{ Year } & \multicolumn{6}{|c|}{ Surgical treatment } & \multirow[t]{2}{*}{ Total } \\
\hline & Cheiloplasty & $\%$ & Palatoplasty & $\%$ & Other $^{\mathrm{a}}$ & $\%$ & \\
\hline 2003 & 11 & 52.4 & 10 & 47.6 & - & - & 21 \\
\hline 2004 & 32 & 46.4 & 32 & 46.4 & 05 & 7.2 & 69 \\
\hline 2005 & 15 & 35.7 & 19 & 45.2 & 08 & 19.1 & 42 \\
\hline 2006 & 16 & 42.1 & 18 & 47.4 & 04 & 10.5 & 38 \\
\hline 2007 & 3 & 100.0 & - & - & - & - & 3 \\
\hline Total & 77 & & 69 & & 17 & & 173 \\
\hline
\end{tabular}

${ }^{\mathrm{a}}$ Fistuloplasty, rhinoplasty, otoplasty.

Table 6 Patient's age at initial assessment in SEAFESE and treatment accomplished

\begin{tabular}{|l|l|l|l|l|}
\hline \multirow{2}{*}{ Age group $(\mathrm{y})$} & \multicolumn{2}{|c|}{ Surgery } & \multirow{2}{*}{ Total } \\
\cline { 2 - 5 } & Lip repair & Palatoplasty & Other $^{\text {a }}$ & \\
\hline$<4$ & 30 & 13 & 01 & $44(21.5 \%)$ \\
\hline $5-09$ & 21 & 14 & - & $35(17.1 \%)$ \\
\hline $10-14$ & 25 & 09 & - & $34(16.6 \%)$ \\
\hline $15-19$ & 22 & 15 & 03 & $40(19.5 \%)$ \\
\hline $20-24$ & 15 & 07 & 01 & $23(11.2 \%)$ \\
\hline$>25$ & 15 & 11 & 03 & $29(14.1 \%)$ \\
\hline
\end{tabular}

SEAFESE, Service Specializing in Cleft Care of Sergipe.

${ }^{a}$ Fistuloplasty, rhinoplasty, otoplasty.

and significant aesthetic and functional gains that will resonate on the quality of life, reflecting on the family.

The demographic profile of the population studied is an individual male (54.0\%), pheoderma (47.2\%), between 0 and 14 years $(77.4 \%)$, who lives in the countryside (58.0\%). In other studies similar results were observed, where the majority of subjects with oral clefts were males, ${ }^{12-14}$ lived in metropolitan areas, and were brown. ${ }^{15}$

The data showed the prevalence of transincisive foramen cleft. These results are similar to a study conducted in Recife, where a predominance of the transincisive foramen cleft (49\%) was observed, followed by postforamen (27\%) and preforamen (24\%) clefts. ${ }^{15}$ Freitas et al observed in São Paulo that the most common types of cleft lip and/or palate were trans- and postforamen (31.7\%), followed by preforamen (28.4\%) and rare fissure (3.8\%). ${ }^{16}$ In other countries a similar prevalence was observed. In Germany, Kramer et al found that the transforamen $(42.4 \%)$ cleft was most often observed, followed by preforamen (28.8\%) and postforamen (28.8\%) clefts. ${ }^{11}$ Sagheri et al, also in Germany, found that the transforamen $(45.9 \%)$ cleft was observed most often, followed by postforamen (41\%) and preforamen (9.8\%) clefts and PierreRobin syndrome (3.3\%). ${ }^{17}$

The cleft lip and/or palate may be present as isolated deformities (or nonsyndromic clefts) or within the phenotype of a syndrome, called syndromic clefts. ${ }^{15}$ Several studies suggest that 30 to $40 \%$ of cases occur as a pattern of multiple malformations and are classified as a known syndrome related to chromosomal alterations, Mendelian disorder, or exposure to a known teratogen. ${ }^{18}$ In this research, associated malformations and complications occurred in 41 individuals, and the data found in this study agree with the findings of Baptista, ${ }^{15}$ Milerad et al, ${ }^{19}$ Ellis, ${ }^{20}$ and Nunes et al. ${ }^{21}$

Data about prenatal care outlined in this study showed accompanying of almost half the analyzed sample and only $7.0 \%$ stated no kind of accompanying. This prevalence is lower than that found in other countries. In France the prenatal diagnosis of cleft occurs in $62.8 \%$ of cases, ${ }^{22}$ in the United States the prevalence is $16 \%,{ }^{23}$ and in England the prevalence is $30 \%{ }^{24}$ Most parents who have a prenatal diagnosis felt that the diagnosis prepared them psychologically for the birth of the child with cleft. ${ }^{24}$

Such data suggest that the primary health care policy adopted by the government, at least in terms of awareness, has been characterized by reforming the potential of primary care in favor of better health outcomes, which caused significant changes in health practice, even though 156 (45.0\%) medical records do not have report data about prenatal care.

Although the increased demand for care in SEAFESE is by children between 0 and 4 years, with a high rate of newborns who have not been subjected to any type of surgery, there was a high number of patients who reported at first visit having already had previous surgery to correct cleft lip and/or palate in another institution. Besides, it was found that in the 0- to 4year group, 44 surgeries had already occurred, followed by 40 surgeries in the 15- to 19-year group. These data confirm that the demand for treatment of cleft patients is taking place at the right time, which is in the first months/years of life. 


\section{Conclusions}

In conclusion, the few epidemiologic studies on cleft in Brazil highlight the importance and need for studies that address determinants of developmental defects, such as oral cleft. In this study, male gender was the most affected, and the age group 0 to 4 years was the most frequent. Transincisive foramen cleft type was most frequently found. Prenatal care was reported by most mothers. So, this study found that early treatment is a reality in SEAFESE; therefore the chances of successful integration of the child to society will be better.

\section{References}

1 Cobourne MT. The complex genetics of cleft lip and palate. Eur J Orthod 2004;26:7-16

2 Munz SM, Edwards SP, Inglehart MR. Oral health-related quality of life, and satisfaction with treatment and treatment outcomes of adolescents/young adults with cleft lip/palate: an exploration. Int J Oral Maxillofac Surg 2011;40:790-796

3 Donkor P, Plange-Rhule G, Amponsah EK. A prospective survey of patients with cleft lip and palate in Kumasi. West Afr J Med 2007;26:14-16

4 Poletta FA, Castilla EE, Orioli IM, Lopez-Camelo JS. Regional analysis on the occurrence of oral clefts in South America. Am J Med Genet A 2007;143A:3216-3227

5 Tan KB, Tan KH, Yeo GS. Cleft deformities in Singapore: a populationbased series 1993-2002. Singapore Med J 2008;49:710-714

6 Freitas e Silva DS, Mauro LDP, Oliveira LB, et al. Estudo descritivo de fissuras lábio-palatinas relacionadas a fatores individuais, sistêmicos e sociais. RGO 2008;56(4):387-391

7 Rodrigues K, Sena MF, Roncalli AG, Ferreira MA. Prevalence of orofacial clefts and social factors in Brazil. Braz Oral Res 2009;23: 38-42

8 Ministério da Saúde. Brazil: DATASUS. Available at: http://tabnet. datasus.gov.br/cgi/tabcgi.exe?sinasc/cnv/nvuf.def. Accessed March 22, 2012

9 IBGE. Instituto Brasileiro de Geografia e Estatística. Regiões de Influência das Cidades. 2007. Available at: http://www.ibge.gov. br/home/geociencias/geografia/regic.shtm. Accessed May 5, 2012

10 Spina V, Psillakis JM, Lapa FS, Ferreira MC. Classificação das fissuras lábio-palatinas. Sugestão de modificação. Rev Hosp Clin Fac Med Sao Paulo 1972;27:5-6
11 Kramer FJ, Gruber R, Fialka F, Sinikovic B, Hahn W, Schliephake H. Quality of life in school-age children with orofacial clefts and their families. J Craniofac Surg 2009;20:2061-2066

12 Ajike SO, Adebola RA, Efunkoya A, Adeoye J, Akitoye O, Veror N. Epidemiology of adult cleft patients in North-western Nigeria: our experience. Ann Afr Med 2013;12:11-15

13 Martelli DR, Machado RA, Swerts MS, Rodrigues LA, Aquino SN, Martelli Júnior $H$. Non syndromic cleft lip and palate: relationship between sex and clinical extension. Braz J Otorhinolaryngol 2012;78:116-120

14 Costa CH, Diniz LV, Lacerda RH, Forte FD, Sampaio FC. Prevalence of dental anomalies in patients with cleft lip and palate, Paraiba, Brazil: clinic and radiographic study. Acta Odontol Latinoam 2012;25:181-185

15 Baptista EVP. Malformações congênitas associadas à fissura labial e/ou palatal em pacientes atendidos em um serviço de referência para tratamento de defeitos da face: um estudo de série de casos [dissertation]. Recife, Brazil: Instituto Materno Infantil Prof. Fernando Figueira; 2007:67

16 Freitas JA, Dalben GdaS, Santamaria M Jr, Freitas PZ. Current data on the characterization of oral clefts in Brazil. Braz Oral Res 2004;18:128-133

17 Sagheri D, Ravens-Sieberer U, Braumann B, von Mackensen S. An Evaluation of Health-Related Quality of Life (HRQoL) in a group of 4-7 year-old children with cleft lip and palate. J Orofac Orthop 2009;70:274-284

18 Dixon MJ, Marazita ML, Beaty TH, Murray JC. Cleft lip and palate: understanding genetic and environmental influences. Nat Rev Genet 2011;12:167-178

19 Milerad J, Larson O, PhD D, Hagberg C, Ideberg M. Associated malformations in infants with cleft lip and palate: a prospective, population-based study. Pediatrics 1997;100(2 Pt 1):180-186

20 Ellis E. Cirurgia Oral e Maxilofacial Contemporânea. 4th ed. Rio de Janeiro, Brazil: Elsevier; 2005

21 Nunes LMN, Queluz DP, Pereira AC. Prevalência de fissuras labiopalatais no município de Campos dos Goytacazes-RJ, 1999-2004. Rev Bras Epidemiol 2007;10(1):109-116

22 Guyot A, Soupre V, Vazquez MP, et al. [Prenatal diagnosis of cleft lip with or without cleft palate: retrospective study and review]. J Gynecol Obstet Biol Reprod (Paris) 2013;42:151-158

23 Matthews MS, Cohen M, Viglione M, Brown AS. Prenatal counseling for cleft lip and palate. Plast Reconstr Surg 1998;101:1-5

24 Davalbhakta A, Hall PN. The impact of antenatal diagnosis on the effectiveness and timing of counselling for cleft lip and palate. $\mathrm{Br} \mathrm{J}$ Plast Surg 2000;53:298-301 